\title{
Assessment of knowledge, attitude and practice towards scabies among medical students in Kingdom of Saudi Arabia, 2018 Ohoud Mohammed ALshehri ${ }^{1}$,Rawabi Abdullah Alharbi ${ }^{2}$, Bayan Mohammed ALsoraya ${ }^{3}$
}

1-Taif University, 2-Umm al qura University, 3-Qassim University (Unizah college of medicine)

\begin{abstract}
$\underline{\text { Abstract }}$
Background: The adequate knowledge about scabies and its preventive measures are important for diagnosis and managing scabies.

Objectives: Evaluating the knowledge, attitude and practice of scabies among medical students in Kingdom of Saudi Arabia (KSA).

Methods: A cross sectional study that was conducted at KSA, for 4 months from May to August 2018. The study included 445 medical Saudi students from both genders. A self-administrated questionnaire was distributed among all the participants.

Results: The study included 445 medical students from different parts of KSA in which the level of knowledge among them regarding scabies and its preventive measures was adequate among most of the participants regarding the causative agents, features of scabies, its associated spreading factors and diagnosis. The attitude and practice of most of the subjects were positive.

Conclusion: This study showed a satisfactory level of knowledge, attitude and practice among medical students in KSA regarding scabies, clinical characteristics and its preventive measures.
\end{abstract}

Keywords: Knowledge, Attitude, Practice, scabies, medical students, Kingdom of Saudi Arabia (KSA).

\section{Introduction:}

Scabies is a skin infestation caused by parasitic mite which is associated with itching, lesions and rashes ${ }^{(\mathbf{1})}$. It is not a life threatening disease but its incidence is high reaching about 300 million around the worldwide ${ }^{(2)}$. Its infestation and outbreaks cause high burden on the authority health costs which is hard to be controlled and treated ${ }^{(3,4)}$.

Scabies can affect both genders and all ages from children to adults as well. It is associated with poor health conditions as poverty, overcrowding and poor hygiene ${ }^{(5,6)}$.

It can be transmitted by person to person by direct contact and its classic symptoms are pruritus which become worth during night, hypersensitivity and other complications including impetigo, septicemia,abscesses, folliculitis, cellulitis, and may result in death ${ }^{(7}$, 8).

The scabies can be misdiagnosed as it can mimic other skin diseases thus, kin scraping is the best diagnostic method ${ }^{(9)}$. The adequate knowledge about scabies and its preventive measures are important for managing scabies. Thus, this study aimed at evaluating the knowledge, attitude and practice of scabies among medical students in KSA.

\section{Methods:}

Study design:
This was a across sectional study that was conducted at KSA, for 4 months from May to August 2018.

Study population and sample size:

The sample size was randomly selected from 13 random Universities from which 35 medical students were randomly chosen from the $6^{\text {th }}$ class. The study included 445 medical Saudi students from both genders.

Study

tools:

A self-administrated questionnaire was conducted, reviewed and developed to assess the medical students' knowledge attitude and practice pattern.

\section{Ethical approval:}

The study was approved by the Ethical Committee of Faculty of medicine. The participants provided a written informed consent of their approval.

\section{Statistical analysis:}

The data were processed using the Statistical Package for Social Sciences (SPSS, version 22) for windows. The variables were presented as frequencies and percentages.

\section{Results:}

Assessment of knowledge: 
The study included 445 medical students from different parts of KSA in which the level of knowledge among them regarding scabies and its preventive measures was adequate among most of the participants regarding the causative agents, features of scabies and its associated spreading factors. Also, most of the participants knew that scabies can be diagnosed by skin scraping but can't be diagnosed neither by blood culture nor stool analysis.

Table (1): Awareness level among medical students (445):

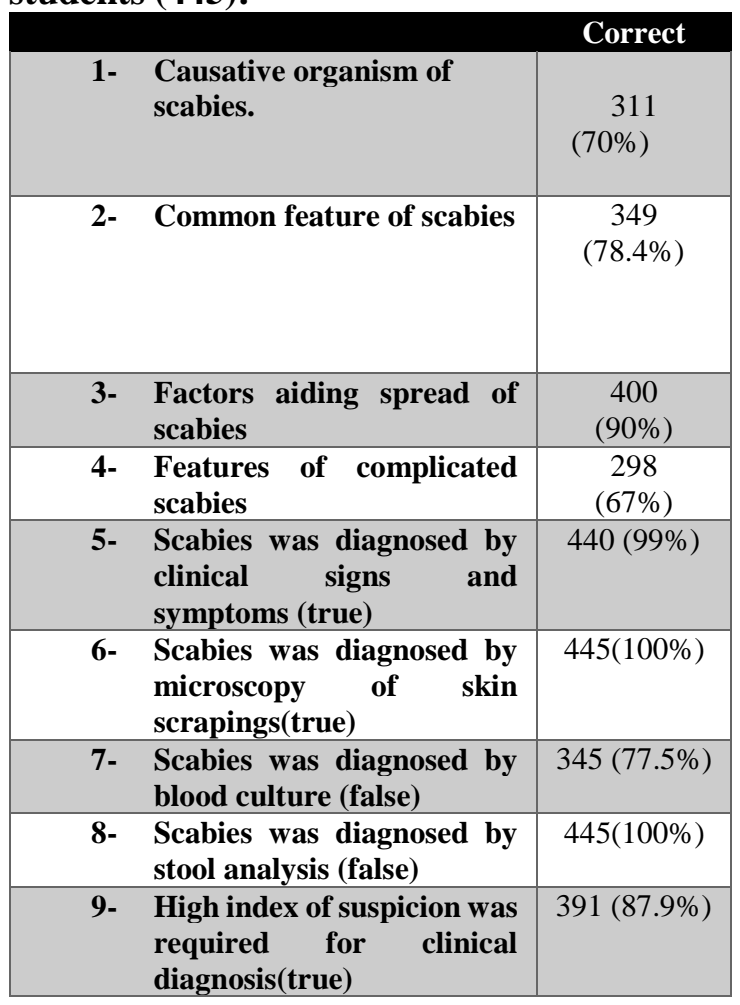

\section{Level of knowledge:}

The level of knowledge was adequate among the majority of medical students (Table. 2).

Table (2): Level of knowledge regarding scabies:

\begin{tabular}{|c|c|c|}
\hline Knowledge level & Frequency & Percent $(\%)$ \\
\hline Good & 382 & 85.8 \\
Poor & 63 & 14.2 \\
Total & 445 & 100.0 \\
\hline
\end{tabular}

- Evaluation of the attitude towards scabies prevention:

The attitude of most of the subjects was positive as presented in Table. (3).
Table (3): Attitude of medical students toward scabies

\begin{tabular}{|l|c|c|}
\hline \multicolumn{2}{|c|}{ No. $\begin{array}{c}\text { Percentage } \\
(\%)\end{array}$} \\
$\begin{array}{l}\text { Mattresses and pillows } \\
\text { are dried every week }\end{array}$ \\
\hline Yes & 445 & 100 \\
\hline No & 0 & 0 \\
\hline $\begin{array}{l}\text { Scabies sufferers have to } \\
\text { be isolated }\end{array}$ & & \\
\hline Yes & 445 & 100 \\
\hline No & 0 & 0 \\
\hline $\begin{array}{l}\text { Scabies patients do need to } \\
\text { be avoided }\end{array}$ & & \\
\hline Yes & 445 & 100 \\
\hline No & 0 & 0 \\
\hline
\end{tabular}

\section{Practice pattern of included subjects:}

The level of practice was sufficient among most of medical students regarding the preventive measure of scabies.

Table (4): practice pattern among medical students:

\begin{tabular}{|ll|c|c|}
\hline \multicolumn{2}{|c|}{ Yes } & No \\
\hline 1. & $\begin{array}{l}\text { Assign patient to a } \\
\text { private room. }\end{array}$ & $\begin{array}{c}445 \\
(100 \%)\end{array}$ & $0(0 \%)$ \\
\hline 2. & $\begin{array}{l}\text { Restrict visitors until } \\
\text { treatment regimen } \\
\text { completed. }\end{array}$ & $\begin{array}{c}398 \\
(89.4 \%)\end{array}$ & $\begin{array}{c}47 \\
(10.6 \%)\end{array}$ \\
\hline 3. & $\begin{array}{l}\text { Scabies can be } \\
\text { prevented by } \\
\text { maintaining a good } \\
\text { personal hygiene. }\end{array}$ & $\begin{array}{c}445 \\
(100 \%)\end{array}$ & $0(0 \%)$ \\
\hline 4. & $\begin{array}{l}\text { If there are cases of } \\
\text { scabies, treatment } \\
\text { should be done quickly } \\
\text { to prevent the } \\
\text { transmission of disease. }\end{array}$ & $\begin{aligned} 445 \\
(100 \%)\end{aligned}$ & $0(0 \%)$ \\
\hline
\end{tabular}

\section{Discussion}

This is the first descriptive study which was conducted in KSA to study the KAP of medical students toward scabies and its preventive measures. The study showed a satisfactory level of knowledge about scabies causative agents, risk factors, features, diagnosis and prevention. In the same respect, a study was conducted among nurses in Gazan. The level of KAP was adequate among most of the participants (10). Also, another study on the knowledge and management of scabies in general practitioners and dermatologists showed a good level of knowledge among most of the participants ${ }^{(11)}$. 
In accordance, another similar study carried out in Western Europe showed that general practitioners and dermatologists have acceptable knowledge regarding scabies with a high scores among dermatologists ${ }^{(\mathbf{1 2})}$.

These results are in contrast to those of a study conducted in Nigeria among 500 medical students in which the level of knowledge was unsatisfactory among most of the subjects though the diseases is endemic ${ }^{(13)}$.

Also, a Pakistani study presented a general lack of knowledge about scabies among general practitioners which resulted in a high prevalence of scabies in their community ${ }^{(\mathbf{1 4})}$.

The level of attitude and practice were adequate among most of subjects which could be attributed to the sufficient level of knowledge among them.

One limitation of this study is the scanty or rare data about this scabies among the medical students in KSA.

\section{Conclusion:}

This study showed a satisfactory level of knowledge, attitude and practice among the medical students in KSA regarding scabies, clinical characteristics and its preventive measures.

\section{References:}

1.Rosamilia LL (2014): Scabies. Semin Cutan Med Surg., 33:106-109.

2.Chosidow O (2006): Clinical practices. Scabies. N Engl J Med., 354:1718-1727.

3.Edison L, Beaudoin A, Goh L et al. (2015): Scabies and Bacterial Superinfection among American Samoan Children, 2011-2012. PLoS One, 10:e0139336.

4.Mounsey KE and McCarthy JS (2013): Treatment and control of scabies. Curr Opin Infect Dis., 26:133-139.

5.Cassell JA, Middleton J, Nalabanda A et al. (2018): Scabies outbreaks in ten care homes for elderly people: a prospective study of clinical features, epidemiology, and treatment outcomes. Lancet Infect Dis., 18:894-902.

6.Hewitt KA, Nalabanda A and Cassell JA (2015): Scabies outbreaks in residential care homes: factors associated with late recognition, burden and impact. A mixed methods study in England. Epidemiology and infection, 143:1542-1551.

7.Romani L, Koroivueta J, Steer AC et al. (2015): Scabies and impetigo prevalence and risk factors in Fiji: a national survey. PLoS neglected tropical diseases, 9:e0003452.

8.Romani L, Steer AC, Whitfeld MJ et al. (2015): Prevalence of scabies and impetigo worldwide: a systematic review. Lancet Infect Dis., 15:960-967.

9.Monsel $G$ and Chosidow $O$ (2012): Management of scabies. Skin Therapy Lett., 17:1-4.

10.Bilal M AH, Medawi A and Mahmoud MA (2018): Knowledge, Attitude and Practice in Preventing Transmission of Scabies among Nurses Students at Sabia University College Jazan University 2018. Austin J Nurs Health Care, 5:1043.

11.Lapeere H, Brochez L, De Weert J et al. (2005): Knowledge and management of scabies in general practitioners and dermatologists. European Journal of Dermatology, 15:171-175. 12.Lapeere H, Brochez $\mathrm{L}$, De Weert $\mathrm{J}$ et al. (2005): Knowledge and management of scabies in general practitioners and dermatologists. Eur J Dermatol., 15:171-175.

13.Sule HM, Hassan ZI, Gyang MD et al. (2015): Knowledge of Scabies Among a Cohort of Medical Students. Open Science Journal of Clinical Medicine, 3:177-181.

14. Rathi SK, Rathi HS, Lakhani H et al. (2001): Awareness about scabies among general medical practitioners (GPs) of Karachi, Pakistan. JPMA The Journal of the Pakistan Medical Association, 51:370-372. 